\title{
How do they debunk "fake news"? A cross-national comparison of transparency in fact checks
}

\author{
Humprecht, Edda
}

\begin{abstract}
Fact-checking has gained importance in recent years, as so-called "fake news" has started to spread on social media. News outlets and independent organizations engage in debunking to combat the massive spread of disinformation. However, several authors have argued that fact checkers can only be successful if they win the trust of the audience - by making their practices transparent. This article analyzes the degree of source transparency provided by eight fact checkers from different countries (the US, the UK, Germany, and Austria). The findings show major differences among the outlets studied which can be attributed to varying levels of journalistic professionalism as well as to organizational differences. Implications for the success of fact-checking and solutions to combat online disinformation are discussed.
\end{abstract}

DOI: https://doi.org/10.1080/21670811.2019.1691031

Posted at the Zurich Open Repository and Archive, University of Zurich

ZORA URL: https://doi.org/10.5167/uzh-177058

Journal Article

Accepted Version

Originally published at:

Humprecht, Edda (2020). How do they debunk "fake news"? A cross-national comparison of transparency in fact checks. Digital Journalism, 8(3):310-327.

DOI: https://doi.org/10.1080/21670811.2019.1691031 


\title{
How Do They Debunk "Fake News"? A Cross-National Comparison of Transparency in Fact Checks
}

\author{
Edda Humprecht \\ University of Zurich
}

\begin{abstract}
Author's Note
Edda Humprecht is a senior research and teaching associate at the Institute of Mass Communication and Media Research, University of Zurich.
\end{abstract}

Correspondence concerning this paper can be sent to Edda Humprecht, Institute of Mass Communication and Media Research, University of Zurich, Andreas St. 15, 8050 Zürich, Switzerland. E-mail to edda.humprecht@uzh.ch, phone: +4144635 2042. 


\title{
How Do They Debunk "Fake News"?
}

\section{A Cross-National Comparison of Transparency in Fact Checks}

\begin{abstract}
Fact-checking has gained importance in recent years, as so-called "fake news" has started to spread on social media. News outlets and independent organizations engage in debunking to combat the massive spread of disinformation. However, several authors have argued that fact checkers can only be successful if they win the trust of the audience - by making their practices transparent. This article analyzes the degree of source transparency provided by eight fact checkers from different countries (the US, the UK, Germany, and Austria). The findings show major differences among the outlets studied which can be attributed to varying levels of journalistic professionalism as well as to organizational differences. Implications for the success of fact-checking and solutions to combat online disinformation are discussed.
\end{abstract}

Keywords: fact-checking, transparency, professionalism, international comparison, content analysis

\section{Introduction}

The role of online disinformation has been intensively discussed in the aftermath of the 2016 US presidential election and the UK vote to leave the European Union ('Brexit') (Allcott \& Gentzkow, 2017; Lazer et al., 2018; Lewandowsky, Ecker, \& Cook, 2017; Vosoughi, Roy, \& Aral, 2018). Although it is controversial whether disinformation has actually influenced voter behavior (Allcott \& Gentzkow, 2017; Fletcher, Cornia, Graves, \& Nielsen, 2018; Nelson \& Taneja, 2018), policy-makers, journalists and scholars have raised questions about how the problem of online disinformation can be solved (High level Group on fake news and online disinformation, 2018). To combat attempts at manipulation and to 
debunk false information, an increasing number of fact-checking platforms have appeared in recent years (Amazeen, 2017; Ciampaglia, 2017; Haigh, Haigh, \& Kozak, 2017; Thorson, 2016; Young, Jamieson, Poulsen, \& Goldring, 2018). The first fact-checking organizations were launched in the US in the early 2000s. Graves and Cherubini (2016) found that the number of European fact-checkers has increased substantially since 2010. Some fact-checking outlets are subunits of established news organizations, often operating only occasionally. However, a majority of these outlets are independent or run by a civil society organization (Graves \& Cherubini, 2016).

The goal that most fact-checkers — both independent and editorial—share is the promotion of truth in public discourse. However, political fact-checking is often controversial and fact-checkers are frequently under attack (Nyhan \& Reifler, 2012; Young et al., 2018). Basic questions are raised, such as what counts as reliable data, who has the authority to assess public truth, and how this truth is balanced. Partisans have been found to refuse factchecks when they contradict their own opinions (Shin \& Thorson, 2017). Brandtzaeg and Folstad (2017) argue that to strengthen trust, fact-checkers should strive to increase transparency. However, little is known about whether and how fact-checkers provide transparency and what organizational and structural characteristics shape their practices. The current study aims to fill this gap by analyzing the source transparency of different types of fact-checking organizations based in different countries. Since there is a great variety of factcheckers in Europe and the USA, the categorization of these organizations poses a great challenge. This paper attempts to categorize fact checkers by examining the organizations with the broadest reach that come closest to the theoretical types. However, due to the heterogeneity of the fact-checker landscape, no representativeness can be established. Rather, this study shows how frequently used fact checkers from different countries work. Thus, the study provides a first insight into the kind of fact-checking and verification that is presented to audiences in different countries. To do so, hypotheses will be tested that link characteristics of 
the information environment, the fact-checking organizations and the content of fact-checks themselves with the degree to which fact-checkers provide information about and access to their sources.

\section{Literature Review}

\section{Transparency in Journalism}

Transparency is considered to be an important aspect of the professionalization of journalism (Phillips, 2010; Revers, 2014). Transparency has been described as a way of truthtelling (Singer, 2010). Kovach and Rosenstiel (2007) argued that claims of journalistic 'truth' must be based on transparency to distinguish journalists from other content producers. According to those authors transparency involves openness to practices of gathering, organizing, and disseminating information to allow the news production process to become visible. Following this rationale, transparency makes journalists reliable, trustworthy, and respectful to audiences. For instance, when journalists present themselves on Twitter, they promote participatory transparency by enabling and implicitly inviting others to become involved in the news production process (Karlsson, 2010).

Definitions of transparency as a journalistic norm often include two aspects namely, openness and accountability (Karlsson, 2011; Singer, 2007). Openness means that journalists make their practices visible and enable audiences to monitor, check, criticize, and even intervene in the journalistic process (Deuze, 2005). In this vein, Singer (2007) outlines the connection between transparency and social accountability and responsibility by journalists. According to Karlsson (2010), two types of transparency can be identified: disclosure transparency and participatory transparency. Disclosure transparency involves "whether news producers are being open about how news is being produced", while participatory transparency" aims at getting the audience involved in the news production process" (Karlsson, 2010, p. 538). Allen (2008, p. 323) has emphasized similar aspects and concludes, 
that "journalistic transparency can be defined as making public the traditionally private factors that influence the creation of news."

The rise of digital communication technologies and digital publishing is argued to have renewed the demand for transparency because it has changed the way journalists interact with their audiences. According to Hellmüller et al. (2013), online journalists believe that readers' contributions to news content add to journalists' truth-telling strategy. Allen (2008) argues that maintaining professional autonomy in the (networked) public sphere requires transparency to legitimize efficacy in journalism. Consequently, there is a growing insistence on the disclosure of information and openness of procedures by audiences (Revers, 2014). Moreover, the professional concern for audience engagement and the economic concern for consumer loyalty mutually reinforce each other, concurrently strengthening transparency (Revers, 2014).

To meet their audiences' demand, fact-checkers have been advised to present the findings of their rigorous research in a comprehensive way (Graves, 2013). For example, the code of principles of the International Fact-Checking Network at Poynter highlight the importance of transparency regarding the methodology of fact-checking, the funding and organization, and, most importantly, the sources (Poynter, 2019). Fact-checkers should use credible sources, such as statements by experts, external documents, graphics, or other types of background information e.g., historical or geographical data (Nyhan \& Reifler, 2012). By making these sources accessible, fact-checkers enable their audiences to retrace their work and - ideally — come to the same evaluation of the information in question.

\section{Evolution and Models of Fact-Checkers}

Fact-checking was first established in the US followed by a diffusion of these practices to Europe. Allcott and Gentzkow (2017) argued that in the US the awareness among journalists and the public towards the problem of disinformation developed long before the 
2016 election and had led to an early emergence of fact-checkers. The early adoption of fact checking practices in the US is argued to be linked to the steady decrease in trust in the news media (Jones, 2004; Strömbäck, Djerf-Pierre, \& Shehata, 2015). The media landscape is increasingly polarized, leading to mistrust among users against publications from the opposite side of the political spectrum (Del Vicario et al., 2016; Miller, Saunders, \& Farhart, 2016; Yang et al., 2016). Furthermore, it can be assumed that the comparatively high level of journalistic professionalism played a role in this development. (Brüggemann, Engesser, Büchel, Humprecht, \& Castro, 2014). American journalists started earlier than their European counterparts to systematically verify claims, e.g., those by politicians. Moreover, they aimed to provide 'objective', nonpartisan information and corrections, especially in times of crises or elections (Graves, 2016). Research on fact-checking has established a link between journalistic professionalism and the development of fact-checking. For instance, Graves et al. (2016) found that fact-checking is driven mainly by professional motives. Those authors conducted a field experiment to test under which conditions journalists were most likely to conduct fact-checking. They presented journalists with messages highlighting either the prestige that fact-checking enjoys within the profession (e.g., references to award-winning fact-checkers) or the demand for fact-checking by audiences (e.g., market research). Their results suggested that messages promoting journalistic values increased the publication of fact checks from newsrooms.

In the US and Europe, different types of fact-checkers have emerged. Graves and Cherubini (2016) generally distinguish two models of fact-checkers, namely, the 'newsroom model' and the 'NGO model'. The newsroom model contains fact-checking organizations affiliated with an established media company. Although only a minority of fact-checkers in Europe belongs to this model, these fact-checkers often have a wide reach (Graves \& Cherubini, 2016). In Germany, for example, the public broadcaster ARD operates its own fact-checking website. And in many other countries, large daily newspapers run fact check in 
the run-up to elections, including The Guardian in the UK. Moreover, they have a competitive advantage because they can rely on editorial resources and the infrastructure of their media parent. However, fact-checkers belonging to the newsroom model are reliant on the editorial interests and financial support of their media parent. The NGO model, in contrast, involves fact-checkers that operate independently of traditional newsrooms. Those organizations are free of the editorial and business constraints of established media outlets but lack the editorial resources and reliable audiences. However, some of these organizations have managed to establish themselves in national media markets. Those outlets are completely independent, are projects of established NGOs, or are linked to universities. The motives of outlets belonging to the different models arguably differ. While many journalists working in established newsrooms perceive fact-checking as part of their journalistic duty (Brandtzaeg, Følstad, \& Chaparro Domínguez, 2017), independent organizations often perceive fact-checking as a "vehicle for political and media reform" (Graves \& Cherubini, 2016, p. 6). Such fact-checkers seek to fill a niche in increasingly polarized media environments by providing nonpartisan information.

For journalists and social media users alike, fact-checking services of interest are those providing analyses and assessments of claims and content in the public domain, such as those analyzed in this study. Those fact-checkers aim to verify claims and statement of relevance for current politics, or target online rumors.

\section{Challenges and Weaknesses}

Previous research has suggested that fact-checkers can help to debunk misinformation and inhibit political lying (Fridkin, Kenney, \& Wintersieck, 2015; Haigh et al., 2017; Young et al., 2018). However, fact-checkers face a number of challenges in their struggle to debunk false information. These challenges differ between fact-checkers belonging to the newsroom model and those belonging to the NGO model. 
Journalists who do fact-checking face problems that apply to the entire field of journalism, such as lack of time and resources, as well as problems that arise from the specific activity. Moreover, journalists often do not have sufficient time for verification and factchecking due to a fast-paced publishing environment and a lack of resources (Brandtzaeg, Lüders, Spangenberg, Rath-Wiggins, \& Følstad, 2016; Silverman, 2015). This insufficiency can lead to uncritically publishing incorrect statements that fuel the dissemination of hoaxes, erroneous claims, and unverified rumors (Lawrence \& Schafer, 2012; Silverman, 2015). As a result, trust in traditional media outlets, already at a historical low across several countries, might be further reduced (Jones, 2004; Newman, Fletcher, Kalogeropoulos, Levy, \& Nielsen, 2017; Vosoughi et al., 2018).

Furthermore, reaching people who believe disinformation is another challenge that all types of fact-checkers must face. Shin and Thorson (2017) found that partisans selectively share fact-checks and thereby create a biased flow of information among their peers. In other words, people believing false information are less likely to see related fact-checks in their social media streams. Moreover, the usage of fact-checking is associated with further individual characteristics. Users with high political knowledge view fact-checking more favorably (Nyhan \& Reifler, 2015). The so-called confirmation bias is another restriction for fact checking since people tend to seek or interpret evidence according to their current beliefs or expectations (Charman, Kavetski, \& Mueller, 2017; Nickerson, 1998). Confirmation bias has been argued to be strong in regard to controversial issues or political beliefs (Taber \& Lodge, 2006), which are often the topics of fact-checkers. Consequently, fact-checking services may miss their target to reduce public deception. More importantly, they might neglect individuals who are most likely to believe false online content and thus would be most in need of fact-checks.

Finally, fact-checks need to be accessible to a broader public. This means, that factcheckers must find ways to articulate their information in a way that is understandable and 
credible. For example, Young et al. (2018) examined different types of fact-checks and found that the format rather than the tone explained their success. Videos were more likely to reduce misperceptions and enabled participants to draw correct inferences because they were perceived as easier to understand than were text-based fact checks. The author concluded that understanding not only the message but also the reasoning behind the evaluation is crucial for the success of fact-checking (Young et al., 2018).

This conclusion is also reflected in the audiences' perception of fact-checking. Brandtzaeg et al. (2016) found that social media users shared ambivalent views on factchecking. While some users highlighted the usefulness of fact-checking services, others expressed strong distrust. Based on these findings, these authors argued that one central aspect to increase the usefulness and trustworthiness of fact-checking services is the transparency of the verification process. Especially in polarized news environments in which individuals tend to mistrust sources publishing information contrary to their own beliefs, transparency is likely to be a necessary condition to make fact-checking successful. Thus, transparent practices transparent can help fact-checkers reach their goals of correcting public misperceptions.

\section{Explaining Different Levels of Transparency in Fact-Checks}

Previous research has shown that it is helpful to take a multi-level perspective to explain varying degrees of transparency in news content (Humprecht \& Esser, 2018b; Karlsson, 2010b). The reason is that news providers are embedded in political and economic environments. Moreover, Reese and Shoemaker (2016) argued that factors on the individual, organizational and social-system levels shape news content and that this perspective can also be adapted to newer media configurations. According to those authors, professionalism is a key concept for explaining differences in news that it operates in different ways across different levels. In this line, several authors argue that trust in the media and journalistic professionalism are closely linked and are mutually reinforcing. (Curry \& Stroud, 2019; 
Pickard, 2011). The audience expects certain journalistic standards and if these are violated, trust can decrease (Reese, 2001). If, however, the standards are met, trust increases. Transparency is one aspect of journalistic professionalization and therefore represents a link between these two concepts. Against this background, this article examines the influences of the different levels in relation to the content produced by fact checkers.

On the macro-level of information environments, journalistic professionalism and low degrees of trust in the news media have been argued to lead to an early adoption of factchecking practices (Graves \& Cherubini, 2016). On the one hand, low levels of trust in the news media make it necessary to provide information that is as objective and factual as possible (Fridkin et al., 2015; Shin \& Thorson, 2017). On the other hand, research has established that journalistic professionalism is linked to the internal and external autonomy of journalists (Brüggemann et al., 2014). This autonomy is reflected, among other things, in the critical assessment and systematic scrutiny of political actors and their claims. Thus, organizations based in these information environments characterized by low levels of trust and high levels of journalistic professionalism are likely to play a pioneering role in professional practices such as source transparency. Against this background, hypotheses are tested on the influence of trust in the news media and journalistic professionalism on compliance with the transparency norm.

Hla: Fact-checkers from countries with high degrees of journalistic professionalism (i.e., the US and Germany) provide higher levels of source transparency compared to factcheckers based in other countries.

$H 1 b$ : Fact-checkers from countries with low degrees of trust in the news media (i.e., the US) provide higher levels of source transparency compared to fact-checkers based in other countries.

Trust in the news media and journalistic professionalism are present to different degrees in the countries under study. However, these hypotheses are not viewed as competing 
because different factors might contribute to high levels of source transparency. The goal of this study is to identify opportunity structures for the provision of transparent fact-checking across countries. Moreover, high levels of journalistic professionalism in a country does not mean that every newsroom has high professional standards. In contrast, several studies have identified shortcomings in news production across the U.S. and Europe (Esser \& Umbricht, 2014; Humprecht \& Esser, 2018a). However, cross-national research has shown that in countries with high levels of journalistic professionalism journalists are more likely to be committed to professional standards, such as transparency (Humprecht \& Esser, 2018b).

On the meso-level, fact-checkers also differ along organizational lines. While factchecking outlets belonging to established news media (newsroom model, see Graves \& Cherubini, 2016) often only operate occasionally, independent fact-checkers (NGO model) see fact-checking as their main task. They focus exclusively on debunking disinformation and thereby try to complement traditional journalism (Brandtzaeg et al., 2016; Graves \& Cherubini, 2016). Moreover, independent fact-checkers often try to distinguish themselves from the national media landscape and seek to provide neutral, non-partisan information. Given their specific mission, those organizations are expected to have an interest in providing source transparency. Thus, the following can be assumed:

H2: Independent fact-checking organizations provide higher levels of source transparency than do their editorial counterparts.

Fact-checkers deal with a wide range of content in their daily work, ranging from statements by politicians to rumors such as the so-called 'pizzagate' incident (Allcott \& Gentzkow, 2017; Ciampaglia, 2017). However, many fact-checking services were founded as a reaction to the massive diffusion of disinformation related to political crises or elections- $\mathrm{a}$ development that started years before the heated debate concerning "fake news" broke out. (Graves \& Cherubini, 2016). Thus, the fact-checking of statements by politicians can be considered a central aspect of fact-checkers' daily work. Moreover, fact checks of statements 
by political actors are likely to be perceived as partisan due to confirmation bias (Winter, Metzger, \& Flanagin, 2016). Against this background, it is assumed that when political actors are concerned fact-checkers are especially eager to be perceived as credible, thus making their sources transparent. In addition, studies have shown that professional standards differ between political and non-political journalism. For example, Boczkowski (2009) showed large differences between soft news and hard news production and found that quality standards are more likely to be used in hard news production. Even though newsrooms may have general quality standards, they are more frequently implemented in political reporting. Thus, I assume that these findings also hold true for fact-checking. "Hard news", such as politics, is more likely to be presented in a transparent way than other topics.

H3: Fact-checkers more frequently provide source transparency when they fact-check statements by political actors compared to statements by nonpolitical actors.

Finally, different evaluations might require different approaches. The attention being paid to and the impact of fact-checking have been found to be highest in the case of negative fact-checks (Fridkin et al., 2015). In order to be credible, fact checkers must justify their evaluation particularly well and prove why a statement is false. In this vein, the level of source transparency can be expected to be high when fact-checkers need to justify why the statement in question is false. Thus, the following hypothesis will be tested:

H4: Fact-checkers more frequently provide source transparency in cases of negative fact checks compared to cases of positive fact checks.

To sum up, this article posits relationships between, on one hand, (a) information environments (as repositories of different degrees of journalistic professionalism and trust in news), (b) types of fact-checking organizations (with different levels of professionalism at the organizational level), (c) the content of fact-checks, and on the other hand, the use of technical features to enhance transparency.

\section{Data}




\section{Sample}

To assess the hypotheses, a quantitative content analysis was conducted. Previous research has shown that are large differences regarding relevant country characteristics exist. Therefore, countries with different levels of journalistic professionalism and trust in the news media were sampled. Comparative studies on these topics have focused primarily on Western European countries and the USA. They show that the USA and Germany have comparatively high levels of journalistic professionalism, while Austria and Great Britain have lower levels of professionalism (Brüggemann et al., 2014). With regard to trust, data from the Digital News Report (2018) shows that trust is particularly high in Germany and particularly low in the USA, while the UK and Austria show average values. This variation makes these countries particularly suitable for testing the hypotheses previously put forward (see Table 1).

In addition, all countries under study, namely the US, the UK, Germany, and Austria, faced important elections or referendums during the investigation period in 2016 and 2017. This is relevant as it was shown that fact checking is particularly frequently used during election times (Fridkin et al., 2015; Shin, Jian, Driscoll, \& Bar, 2016). ${ }^{1}$

In addition to the different levels of professionalization and trust, two additional differences are of interest. First, the majority of previous research on fact checkers is focused on the USA, but less is known about European organizations. Since fact checking first emerged in the USA, it could be assumed that there is a co-orientation in Europe towards the USA. The question is whether different journalistic traditions influence this co-orientation. Second, two English-speaking and two German-speaking organizations were chosen, since spill-over effects are also possible in uniform language areas. This raises the question of the extent to which organizational effects affect these spill-over effects. Data sources included a

\footnotetext{
${ }^{1}$ The "Brexit" referendum in the UK occurred on June 23, 2016, presidential elections in the US occurred on November 8, and presidential elections in Austria occurred on December 4 and in Germany, general elections were held on September 24, 2017
} 
study by Brüggemann et al. (2014) on journalistic professionalism and the Digital News Report for trust in the news media (Newman et al., 2017). Brüggemann et al. (2014) used five indicators to build their index namely, internal autonomy (i.e., the extent to which journalists enjoy professional autonomy from publishers or owners), external autonomy (the extent to which journalists enjoy autonomy from political or economic actors), the existence of professional guidelines (e.g. concerning the protection of confidential sources), media credibility (e.g., the extent to which news media are perceived by audiences to be autonomous), and public orientation (the extent to which journalists are oriented towards serving the public interest). The data originally stems from the European Media System Survey (2010) and the Worlds of Journalism Survey $(2007-2011)^{2}$.

Trust in the news media was measured using data from Reuters Institute's Digital News Report (2017). In a cross-national survey, respondents were asked to indicate their level of agreement with the statements "I think you can trust most news most of the time" and "I think I can trust most of the news I consume most of the time".

\section{[TABLE 1 ABOUT HERE]}

In the second step, in each of the four countries two major fact-checking websites were sampled, one belonging to the NGO model and one belonging to the newsroom model, to test the differences between these types of fact-checking organizations as formulated in Hypothesis 2. A central challenge was to find functional equivalents in very different media environments. To take this issue into account, a multi-stage procedure was applied. First, lists of all fact checkers in all countries were created. Various databases and reports were used for this purpose: the database of global fact-checking sites of the Reporters' Lab at Duke University, the list of signatories of the code of principle of the International Fact-Checking Network at Poynter, and the report on fact-checkers in Europe by Graves \& Cherubini (2016).

\footnotetext{
${ }^{2}$ For more details review Brüggemann et al. (2014).
} 
Even though these databases list the most important fact checkers in different countries, it must be emphasized that it is hardly possible to map a national Fact Checker landscape holistically because the individual organizations in different countries are too heterogeneous. In order to nevertheless make statements about the situation in different countries, organizations were selected for this study that have a high reach and therefore are likely to play an important role in the context of elections.

The fact-checkers identified based on the databases mentioned above were subsequently assigned to either the newsroom model or to the NGO model. Only factcheckers were assigned to the newsroom model who are part of an editorial newsroom. Factcheckers that are loosely associated with a media company but work independently were assigned to the NGO model. This applied for PolitiFact which was affiliated with the Tampa Bay Times. Finally, from each category and for each country, the fact-checkers with the largest reach were determined. This approach ensured that only fact-checkers that reached a critical mass of readers and thus had a certain social relevance were examined. The sample can be viewed in Table 2.

\section{[TABLE 2 ABOUT HERE]}

At the time of the study, four of the eight organizations examined belonged to the Fact-Checkers Network, namely Correctiv, FullFact, Politfact, and the Washington Post. One criterion for inclusion in the network is the provision of source transparency. The sample thus allows to examine whether i) the respective fact checks meet this requirement and ii) to what extent they differ from other fact checkers that do not belong to the network.

In the third step, up to 100 fact-checks were sampled from each of the websites. Only societally relevant fact-checks published between June 1, 2016, and September 30, 2017, were selected $(N=651)$. Societally relevant topics, as opposed to individually relevant topics, covered politics, the economy, or society and/or referred to respective actors (individual or collective) such as politicians or political institutions. To identify these fact-checks and 
sample functional equivalents, similar subpages of the websites were identified. These subpages included statements of politicians and online rumors, satire and disinformation from alternative websites. The subpage "statements" was analyzed for Politifact, the subpage “issues”for the Washington Post, and the subpage "faktenfinder.tagesschau.de" for the German ARD Faktenfinder.. The other websites under study did not have different subpages and sometimes did not even have a distinct subpage for fact-checking in general. Therefore, Google Search was used to identify the number of published fact-checks ${ }^{3}$. For Fullfact, The Guardian, Correctiv, Mimikama, and die Presse, we used the search term "fact check ("Faktencheck" for German-language websites) site:[name of the website]". Based on this step, we randomly sampled up to 100 fact-checks from each website.

\section{Measures}

To test the hypotheses postulated above, a quantitative content analysis was conducted. The concept of transparency has several dimensions (Humprecht \& Esser, 2018b). Based on the literature, this study assumes that transparency is only fully given if several aspects of transparency are present. For this reason, transparency dimensions were measured separately and subsequently combined into an index. Source transparency was operationalized using the four variables, including links to external documents or sources (e.g. statistics, official reports, or databases), links to a news site (e.g. pages of national or international news media), the inclusion of an info graphic or table (e.g. graphical illustration of complex processes), or visuals (e.g. maps, photographs) used as sources for the evaluation. These items were usually located within the published fact check itself, or next to it within the site frame of the website. The indicators were subsequently merged into a formative index. Sources included politicians or speakers of political institutions (not belonging to the national

\footnotetext{
${ }^{3}$ Google News is the most widely used news aggregator in Europe and in the US (Newman et al.,
} 2017). 
government), members of the national government, economic actors, journalists, the general public, or other actors. The content was coded by two bilingual coders who underwent several rounds of coder training until the intercoder reliability test achieved a satisfactory result (see Table 3).

\section{[TABLE 3 ABOUT HERE]}

As explained above, the variables measuring source transparency were merged into an additive index. The hypotheses were examined using univariate analyses of variance (ANOVAs) and t-tests. Moreover, multivariate ordinary least squares (OLS) regression models were used to determine what factors predict source transparency. The independent variables were entered in blocks in order of their relative explanatory power: (1) county-level characteristics, (2) outlet type and (3) content-based predictors.

\section{Findings}

\section{Sample description}

In total, 651 fact-checks published by fact-checking websites between June 1, 2016, and September 30, 2017, were collected. The initial aim was to sample up to 100 fact-checks on each website; however, several websites had published fewer fact-checks within the given time period. In Germany ( $\mathrm{n}=154)$ and Austria $(\mathrm{n}=97)$, the number of published fact-checks within the sampling period was considerably lower than in the English-speaking countries.

\section{Outlet differences}

The results of the analysis show significant differences between the individual organizations examined in this study. The study finds significant differences between the fact checkers from the US and some European organizations. Figure 1 shows the composition of the measured transparency indicators for the different outlets. While links to websites are frequently used by most organizations, links to external documents and sources are only regularly used by some fact checkers. Other forms of transparency, such as graphics or info 
boxes, are not frequently used overall. As discussed above, it is assumed in this study that transparency only exists if at least two or more of the transparency indicators are present. For this reason, a Transparency Index is formed that summarizes all sub-indicators.

\section{[FIGURE 1 ABOUT HERE]}

\section{Country differences}

Transparency, measured via the occurrence of links to external documents or sources, link to news sites, info graphics, tables, visuals, or other sources, is found to differ significantly across the countries and fact-checking types studied. An ANOVA including the Transparency Index shows that German and US-based fact-checking services provide the highest degrees of transparency when publishing their fact-checks (see Table 4). Interestingly, single indicators of the Transparency Index also differ cross-nationally. Fact-checkers based in the US most frequently provide links to external documents or other sources (.86) as well as links to news sites (.81). The use of info graphics and info boxes is less common across all countries but more frequent in German-speaking than in English-speaking countries. Info graphics are used most frequently in Austria (.27), and info boxes are used most frequently in Germany (.42).

\section{[TABLE 4 ABOUT HERE]}

\section{Outlet type differences}

When differences in outlet types were examined, the results also show distinct patterns with regard to source transparency. Independent outlets, also referred to as the 'NGO model' (Graves \& Cherubini, 2016), provide significantly higher degrees of transparency compared to editorial outlets (see Table 5). Independent outlets more frequently link to external documents or sources (.85 vs. .53) and make use of info graphics (.28 vs. .10) than do editorial outlets. Links to news sites and info boxes are used equally by both types of outlets. 
To test the hypotheses guiding this research, a series of ordinary least square (OLS) regressions were run (see Table 6). Hypothesis 1a postulated a relationship between the degree of journalistic professionalism at the national level and the source transparency provided by fact-checking services. This assumption is based on research showing that source transparency is perceived as an important journalistic value (Hellmueller et al., 2013; Karlsson, 2010a). This hypothesis is accepted since Model 1 shows a significant effect of journalistic professionalism on source transparency. Moreover, Hypothesis $1 \mathrm{~b}$ is based on the assumption that fact-checkers in low-trust provide higher levels of transparency. However, in Model 1, trust in the news media does not contribute to the prediction of source transparency. Furthermore, the inclusion of the variable 'independent outlet' in the next model showed a significant effect suggesting that independent outlets more frequently provide source transparency. Consequently, Hypothesis 2 is accepted.

In Model 3, the variables of negative evaluation (fact checks claiming that the statement in question is wrong) and source (political actor as a source of statement) were added to the analysis. The results show that both variables have no significant effect on the source transparency provided by fact-checkers which leads to the rejection of Hypotheses $\mathrm{H} 3$ and $\mathrm{H} 4$.

In the last model, an interaction between the independent outlet and the US is added. This interaction tests the assumption that independent outlets based in low-trust environments, such as the US, more frequently provide source transparency because they need to gain users' trust. Model 4 shows that this interaction negatively associated with an increase in source transparency. Thus, $\mathrm{H} 2 \mathrm{~b}$ is rejected. In Model 4, the explained variance is increased to 21 percent.

[TABLE 6 ABOUT HERE]

\section{Discussion and Conclusion}


Without an accurately informed citizenry, democratic institutions cannot function as intended. Therefore, fact-checking services aim to promote truth in public discourse. Their increased visibility reflects a growing effort to integrate neutral, nonpartisan arbiters of truth into the public sphere to counteract the influence of disinformation and deception. This article compares the level of source transparency in publications from fact-checkers across different countries.

The findings support the assumption that the use of source transparency is linked to characteristics of the information environment and to the type of fact-checking organization. At the national level, journalistic professionalism seems to drive the provision of source transparency. At the organizational level, independent fact-checkers are more likely to make their sources transparent and thereby enable users to understand and trace back the process of correction. Interestingly, there was no significant main effect of the low-trust environment on source transparency. Moreover, a significant negative interaction between low trust in the news media and independent outlets was found indicating that the independent outlets in the US does not outperform the editorial fact checker.

From these results it can be concluded that country differences play an important role in the context of source transparency. However, findings are preliminary, as transparency was only investigated on the basis of a small sample of particularly wide-reaching fact checkers. Therefore, the results of this study must be interpreted with caution and may only offer suggestive evidence for further study.

However, the results allow for further interesting interpretations. They show that fact checkers from the US frequently provide source transparency and thus live up to their pioneering role. It can be assumed that the strong polarization in the country and the struggle for sovereignty over facts forces the organizations to work professionally and transparently in order to reach and convince their audience. Fact checkers from Europe seem to be less 
inclined to do so, even if the growing fact checker landscape would benefit from greater professionalism and credibility.

Furthermore, results show that the organizations belonging to the Fact Checker Network work comparatively transparent. Membership in the network thus seems to secure higher standards. This is an important finding, especially for the public, since such networks can offer important contact points for the verification of information.

Although online disinformation is a global phenomenon, practices of correction still seem to be shaped by national news cultures - in newsrooms as well as in independent organizations. Consequently, from a user's perspective, the possibility of coming across transparent, professional fact-checking depends on the country in which one lives. As the problem of online disinformation becomes more prevalent in several countries, fact-checkers must adapt their practices to make an impact and to reach a critical mass. Professional practices have been found to diffuse across countries over time and therefore the same can be expected for fact-checking (Engesser \& Humprecht, 2015; Rogers, 2003).

This study has several important limitations, most of which stem from its limited sample of fact-checking organizations. To include functional equivalents, only two factchecking outlets per country and only those with a wide reach were sampled. Thus, the results do not reflect the whole variety of fact-checkers in each country. Moreover, the sample is too small to draw decisive conclusions regarding country differences. The fact-checking landscapes in the U.S. and Europe are developing rapidly. There is currently no complete list of all fact-checkers worldwide. To collect fact-checkers with a large readership in each country, different reports and databases were used. However, these sources are most likely incomplete. Furthermore, smaller fact-checkers may exist that would have been better equivalents but only reach few readers.

Finally, only four Western countries were included in the analysis. However, in countries with lower levels press freedom, fact-checking is likely to play an important role in 
correcting public misperceptions (Haigh et al., 2017; Khaldarova \& Pantti, 2016). To identify further relevant factors that can explain the provision of source transparency, a broader country sample is needed. In order to examine the role of journalistic professionalization more closely, future studies should also examine countries with a greater variance in this respect. Furthermore, sample sizes were different across countries because outlets in the Germanspeaking countries published comparatively few fact checks within the sampling period. This difference suggests that fact-checking still plays a less important role than it does in the English-speaking countries.

When interpreting the results it should be taken into account that only, this study only examined source transparency. However, other forms of transparency might also be relevant to help users understand fact-checkers' assessments. Brandtzaeg et al. (2017) argue that the process of the selection of claims and the process of verification itself are important aspects that need to be made transparent to increase the credibility of fact-checkers. These aspects should be taken into account by future studies in this field. Finally, this article builds on the literature claiming that transparency can increase the credibility of fact-checkers and thus make fact-checking more successful (Brandtzaeg \& Følstad, 2017; Graves, 2013). However, in this study, the effects of source transparency on users were not tested. Experimental research is needed to examine whether source transparency indeed increases the perceived credibility of fact checks.

For democracy to function, citizens need accurate information that is accessible and understandable. In an information-saturated and politically polarized world, fact-checkers must find ways to stimulate interest and promote the formation of accurate inferences. Furthermore, the sheer volume and speed in the production and distribution of online disinformation makes it challenging for fact-checkers to keep up. Sharing disinformation often outpaces sharing fact checks. However, fact-checkers are important actors in the battle against online disinformation. As the tentative results of this study show, fact-checkers build 
their assessments on a variety of sources and thereby enable users to access and verify the information themselves.

Finally, this article argues that source transparency is an important aspect in the context of fact-checking. By providing background information on the sources used, factcheckers might be able to gain credibility and thus reach online users who are misled by online disinformation. Newsrooms and independent fact-checking organizations should strive towards professionalization and encourage their employees to make their practices transparent. 


\section{References}

Allcott, H., \& Gentzkow, M. (2017). Social Media and Fake News in the 2016 Election. Journal of Economic Perspectives, 31(2), 211-236.

Allen, D. S. (2008). The trouble with transparency: The challenge of doing journalism ethics in a surveillance society. Journalism Studies, 9(3), 323-340. https://doi.org/10.1080/14616700801997224

Amazeen, M. A. (2017). Journalistic interventions: The structural factors affecting the global emergence of fact-checking. Journalism: Theory, Practice \& Criticism. https://doi.org/10.1177/1464884917730217

Boczkowski, P. J. (2009). Rethinking Hard and Soft News Production: From Common Ground to Divergent Paths. Journal of Communication, 59(1), 98-116. https://doi.org/10.1111/j.1460-2466.2008.01406.x

Brandtzaeg, P. B., \& Følstad, A. (2017). Trust and distrust in online fact-checking services. Communications of the ACM, 60(9), 65-71. https://doi.org/10.1145/3122803

Brandtzaeg, P. B., Følstad, A., \& Chaparro Domínguez, M. Á. (2017). How Journalists and Social Media Users Perceive Online Fact-Checking and Verification Services. Journalism Practice, 2786(October), 1-21. https://doi.org/10.1080/17512786.2017.1363657

Brandtzaeg, P. B., Lüders, M., Spangenberg, J., Rath-Wiggins, L., \& Følstad, A. (2016). Emerging Journalistic Verification Practices Concerning Social Media. Journalism Practice, 10(3), 323-342. https://doi.org/10.1080/17512786.2015.1020331

Brüggemann, M., Engesser, S., Büchel, F., Humprecht, E., \& Castro, L. (2014). Hallin and Mancini Revisited: Four Empirical Types of Western Media Systems. Journal of Communication, 64(6), 1037-1065. https://doi.org/10.1111/jcom.12127

Charman, S. D., Kavetski, M., \& Mueller, D. H. (2017). Cognitive Bias in the Legal System: Police Officers Evaluate Ambiguous Evidence in a Belief-Consistent Manner. Journal of Applied Research in Memory and Cognition, 6(2), 193-202. https://doi.org/10.1016/j.jarmac.2017.02.001

Ciampaglia, G. L. (2017). Fighting fake news: a role for computational social science in the fight against digital misinformation. Journal of Computational Social Science, 1(1), 147-153. https://doi.org/10.1007/s42001-017-0005-6

Curry, A. L., \& Stroud, N. J. (2019). The effects of journalistic transparency on credibility assessments and engagement intentions. Journalism, 146488491985038. https://doi.org/10.1177/1464884919850387

Del Vicario, M., Bessi, A., Zollo, F., Petroni, F., Scala, A., Caldarelli, G., ... Quattrociocchi, W. (2016). The spreading of misinformation online. Proceedings of the National Academy of Sciences, 113(3), 554-559. https://doi.org/10.1073/pnas.1517441113

Deuze, M. (2005). What is journalism?: Professional identity and ideology of journalists reconsidered. Journalism, 6(4), 442-464. https://doi.org/10.1177/1464884905056815

Engesser, S., \& Humprecht, E. (2015). Frequency or Skillfulness. Journalism Studies, 16(4), 513-529. https://doi.org/10.1080/1461670X.2014.939849

Esser, F., \& Umbricht, A. (2014). The Evolution of Objective and Interpretative Journalism in 
the Western Press: Comparing Six News Systems since the 1960s. Journalism \& Mass Communication Quarterly, 91(2), 229-249. https://doi.org/10.1177/1077699014527459

Fletcher, R., Cornia, A., Graves, L., \& Nielsen, R. K. (2018). Measuring the reach of "fake news" and online disinformation in Europe (Factsheet).

Fridkin, K., Kenney, P. J., \& Wintersieck, A. (2015). Liar, Liar, Pants on Fire: How FactChecking Influences Citizens' Reactions to Negative Advertising. Political Communication, 32(1), 127-151. https://doi.org/10.1080/10584609.2014.914613

Graves, L. (2013). Deciding what's true: Fact-checking journalism and the new ecology of news. Columbia University.

Graves, L. (2016). Deciding what's true: The rise of political fact-checking in American journalism. New York, New York, USA: Columbia University Press.

Graves, L., \& Cherubini, F. (2016). The Rise of Fact-Checking Sites in Europe. Oxford, UK: Reuters Institute for the Study of Journalism.

Graves, L., Nyhan, B., \& Reifler, J. (2016). Understanding Innovations in Journalistic Practice: A Field Experiment Examining Motivations for Fact-Checking. Journal of Communication, 66(1), 102-138. https://doi.org/10.1111/jcom.12198

Haigh, M., Haigh, T., \& Kozak, N. I. (2017). Stopping Fake News: The work practices of peer-to-peer counter propaganda. Journalism Studies, O(0), 1-26. https://doi.org/10.1080/1461670X.2017.1316681

Hellmueller, L., Vos, T. P., \& Poepsel, M. A. (2013). SHIFTING JOURNALISTIC CAPITAL?: Transparency and objectivity in the twenty-first century. Journalism Studies, 14(3), 287-304. https://doi.org/10.1080/1461670X.2012.697686

High level Group on fake news and online disinformation. (2018). A multi-dimensional approach to disinformation. Brussels. https://doi.org/10.2759/0156

Humprecht, E., \& Esser, F. (2018a). Diversity in Online News. Journalism Studies, 19(12), 1825-1847. https://doi.org/10.1080/1461670X.2017.1308229

Humprecht, E., \& Esser, F. (2018b). Mapping digital journalism: Comparing 48 news websites from six countries. Journalism, 19(4), 500-518.

https://doi.org/10.1177/1464884916667872

Jones, D. a. (2004). Why Americans Don't Trust the Media: A Preliminary Analysis. The Harvard International Journal of Press/Politics, 9(2), 60-75. https://doi.org/10.1177/1081180X04263461

Karlsson, M. (2010a). Rituals of transparency: Evaluating online news outlets' uses of transparency rituals in the United States, United Kingdom and Sweden. Journalism Studies, 11(4), 535-545. https://doi.org/10.1080/14616701003638400

Karlsson, M. (2010b). Rituals of Transparency. Journalism Studies, 11(May), 535-545. https://doi.org/10.1080/14616701003638400

Karlsson, M. (2011). The immediacy of online news, the visibility of journalistic processes and a restructuring of journalistic authority. Journalism, 12(3), 279-295. https://doi.org/10.1177/1464884910388223

Khaldarova, I., \& Pantti, M. (2016). Fake News: The narrative battle over the Ukrainian conflict. Journalism Practice, 10(7), 891-901. 
https://doi.org/10.1080/17512786.2016.1163237

Lawrence, R. G., \& Schafer, M. L. (2012). Debunking Sarah Palin: Mainstream news coverage of "death panels." Journalism, 13(6), 766-782. https://doi.org/10.1177/1464884911431389

Lazer, D. M. J., Baum, M. A., Benkler, Y., Berinsky, A. J., Greenhill, K. M., Menczer, F., ... Zittrain, J. L. (2018). The science of fake news. Science, 359(6380), 1094-1096. https://doi.org/10.1126/science.aao2998

Lewandowsky, S., Ecker, U. K. H., \& Cook, J. (2017). Beyond Misinformation : Understanding and Coping with the "Post-Truth" Era. Journal of Applied Research in Memory and Cognition, 1-17. https://doi.org/10.1016/j.jarmac.2017.07.008

Miller, J. M., Saunders, K. L., \& Farhart, C. E. (2016). Conspiracy Endorsement as Motivated Reasoning: The Moderating Roles of Political Knowledge and Trust. American Journal of Political Science, 60(4), 824-844. https://doi.org/10.1111/ajps.12234

Nelson, J. L., \& Taneja, H. (2018). The small, disloyal fake news audience: The role of audience availability in fake news consumption. New Media \& Society. https://doi.org/10.1177/1461444818758715

Newman, N., Fletcher, R., Kalogeropoulos, A., Levy, D. A. L., \& Nielsen, R. K. (2017). Reuters Institute Digital News Report 2017. Oxford, UK. https://doi.org/10.1080/21670811.2012.744561

Newman, N., Levy, D., \& Nielsen, R. K. (2018). Reuters Institute Digital News Report 2018. https://doi.org/10.2139/ssrn.2619576

Nickerson, R. S. (1998). Confirmation bias: A ubiquitous phenomenon in many guises. Review of General Psychology, 2(2), 175-220. https://doi.org/10.1037/10892680.2.2.175

Nyhan, B., \& Reifler, J. (2012). Misinformation and Fact-checking: Research Findings from Social Science. New America Foundation, 28.

Nyhan, B., \& Reifler, J. (2015). The Effect of Fact-Checking on Elites: A Field Experiment on U.S. State Legislators. American Journal of Political Science, 59(3), 628-640. https://doi.org/10.1111/ajps.12162

Phillips, A. (2010). Transparency and the New Ethics of Journalism. Journalism Practice, 4(3), 373-382. https://doi.org/10.1080/17512781003642972

Pickard, V. (2011). Can Government Support the Press? Historicizing and Internationalizing a Policy Approach to the Journalism Crisis. The Communication Review, 14(2), 73-95. https://doi.org/10.1080/10714421.2011.573430

Poynter. (2019). International Fact-Checking Network's code of principles. Retrieved from https://ifcncodeofprinciples.poynter.org/

Reese, S. D. (2001). Understanding the Global Journalist. Journalism Studies, 2(2), 173-187. https://doi.org/10.1080/14616700118394

Reese, S. D., \& Shoemaker, P. J. (2016). Media Sociology and the Hierarchy of Influences Model A levels of analysis perspective on the networked public sphere. Mass Communication \& Society, 5436(July), 1-39. https://doi.org/10.1080/15205436.2016.1174268 
Revers, M. (2014). The Twitterization of News Making: Transparency and Journalistic Professionalism. Journal of Communication, 64, 806-826. https://doi.org/10.1111/jcom.12111

Rogers, E. (2003). Diffusion of Innovations (5th ed). New York: Free Press.

Shin, J., Jian, L., Driscoll, K., \& Bar, F. (2016). Political rumoring on Twitter during the 2012 US presidential election: Rumor diffusion and correction. New Media \& Society, 1-22. https://doi.org/10.1177/1461444816634054

Shin, J., \& Thorson, K. (2017). Partisan Selective Sharing: The Biased Diffusion of FactChecking Messages on Social Media. Journal of Communication, 67(2), 233-255. https://doi.org/10.1111/jcom.12284

Silverman, C. (2015). Lies, Damn Lies, and Virtual Content: How News Websites Spread (and Debunk) Online Rumors, Unverified Claims, and Missinformation. New York.

Singer, J. B. (2007). Contested autonomy: Professional and popular claims on journalistic norms. Journalism Studies, 8(1), 79-95. https://doi.org/10.1080/14616700601056866

Singer, J. B. (2010). Norms and the Network: Journalistic Ethics in a Shared Media Space. In C. Meyers (Ed.), Journalism Ethics: A Philosophical Approach (pp. 117-129). New York: Oxford University Press.

Strömbäck, J., Djerf-Pierre, M., \& Shehata, A. (2015). A Question of Time? A Longitudinal Analysis of the Relationship between News Media Consumption and Political Trust. The International Journal of Press/Politics, 21(1), 88 -110. https://doi.org/10.1177/1940161215613059

Taber, C. S., \& Lodge, M. (2006). Motivated Skepticism in the Evaluation of Political Beliefs. American Journal of Political Science, 50(3), 755-769. https://doi.org/10.1111/j.1540-5907.2006.00214.x

Thorson, E. (2016). Belief Echoes: The Persistent Effects of Corrected Misinformation. Political Communication, 33(3), 460-480. https://doi.org/10.1080/10584609.2015.1102187

Vosoughi, S., Roy, D., \& Aral, S. (2018). The spread of true and false news online. Science, 359(March), 1146-1151.

Winter, S., Metzger, M. J., \& Flanagin, A. J. (2016). Selective Use of News Cues: A Multiple-Motive Perspective on Information Selection in Social Media Environments. Journal of Communication, 66(4), 669-693. https://doi.org/10.1111/jcom.12241

Yang, J., Rojas, H., Wojcieszak, M., Coen, S., Curran, J., Iyengar, S., ... Tiffen, R. (2016). Why Are "Others" So Polarized?: Perceived Political Polarization and Media Use in 10 Countries. Journal of Computer Mediated Communication, 21(5), 349-367. https://doi.org/10.1111/jcc4.12166

Young, D. G., Jamieson, K. H., Poulsen, S., \& Goldring, A. (2018). Fact-Checking Effectiveness as a Function of Format and Tone: Evaluating FactCheck.org and FlackCheck.org. Journalism and Mass Communication Quarterly, 95(1), 49-75. https://doi.org/10.1177/1077699017710453 


\section{Tables and Figures}

Table 1: Means of Basic Parameters

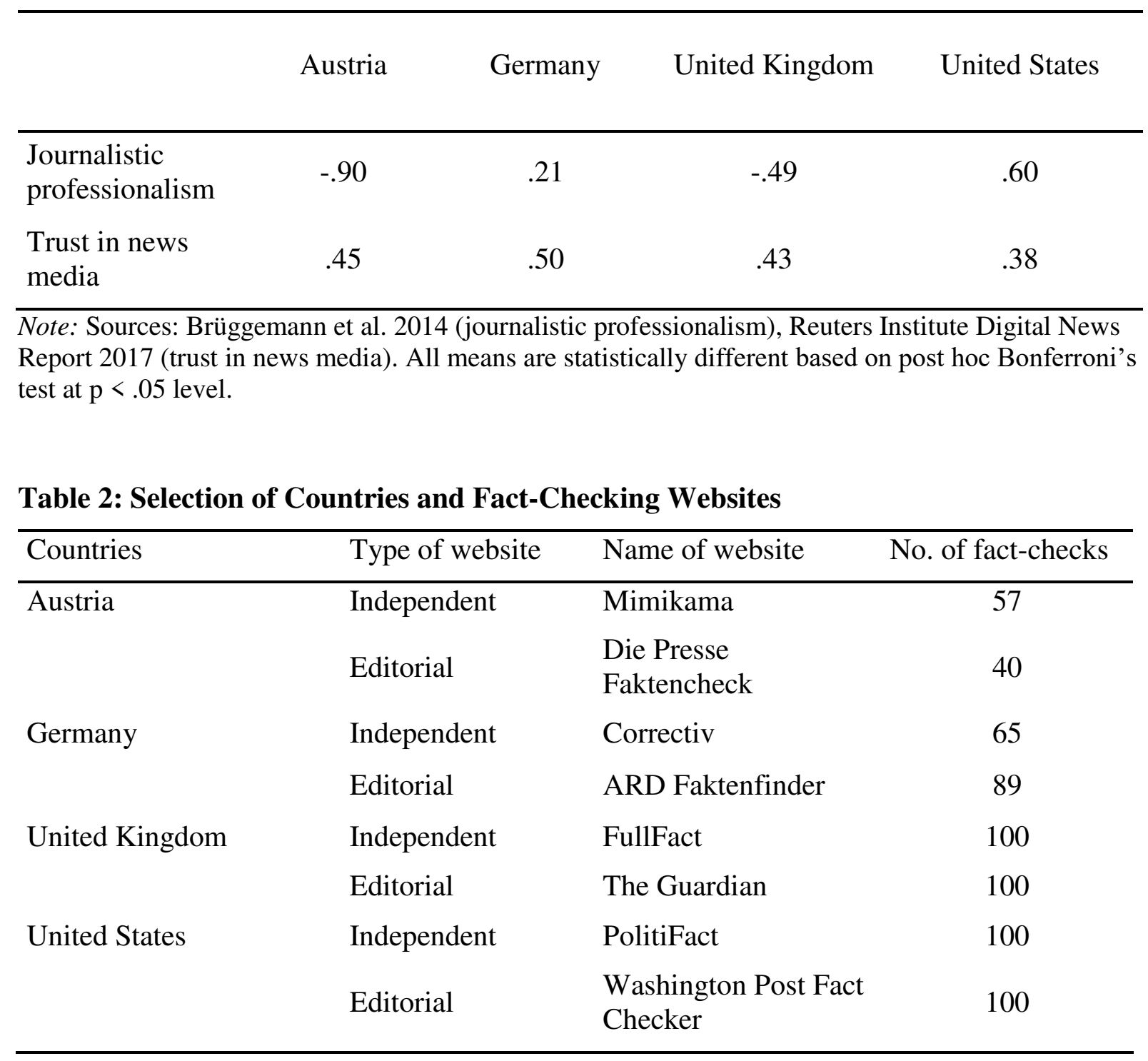

Table 3: Intercoder reliability Scores

\begin{tabular}{lcc}
\hline & Percent agreement & Krippendorff's alpha \\
\hline Link to document/ source & .86 & .70 \\
Link to news site & .86 & .72 \\
Info graphics & 1.00 & 1.00 \\
Visuals & .93 & .64 \\
Other sources & 1.00 & n. a. \\
Source of statement & .82 & .75 \\
Evaluation by fact-checker & .93 & .86 \\
Average & .91 & .78 \\
\hline
\end{tabular}


Table 4: Source Transparency by Country

\begin{tabular}{lccccc}
\hline & AT & DE & UK & US & $F$ values \\
\hline $\begin{array}{l}\text { Transparency } \\
\text { Index }\end{array}$ & 1.10 & $1.97^{\mathrm{a}}$ & 1.60 & $2.17^{\mathrm{a}}$ & 34.71 \\
$\begin{array}{l}\text { Link to document/ } \\
\text { source }\end{array}$ & $.47^{\mathrm{a}}$ & $.55^{\mathrm{a}}$ & .73 & .86 & 23.02 \\
Link to news site & .16 & $.73^{\mathrm{ab}}$ & $.64^{\mathrm{a}}$ & $.81^{\mathrm{b}}$ & 51.16 \\
Info graphics & .27 & $.12^{\mathrm{a}}$ & $.16^{\mathrm{a}}$ & $.22^{\mathrm{a}}$ & 3.61 \\
Info box & $.19^{\mathrm{a}}$ & .42 & .03 & $.25^{\mathrm{a}}$ & 32.25 \\
Other sources & $.01^{\mathrm{a}}$ & .14 & $.05^{\mathrm{a}}$ & $.04^{\mathrm{a}}$ & 8.60
\end{tabular}

Note. Total $\mathrm{N}=651$. Rows present results of separate AVOVAs. Means with the same superscript are not statistically different (based on post hoc Gabriel's test for unequal sample sizes at $\mathrm{p}<.05$ level). Transparency Index (additive index): $0=$ minimum, $5=$ maximum; sub-indicators: $0=$ minimum, $1=$ maximum.

Table 5: Source Transparency by Outlet Type

\begin{tabular}{lccc}
\hline & $\begin{array}{c}\text { Independent } \\
\text { Outlet }\end{array}$ & Editorial Outlet & $p$ \\
\hline Transparency Index & $1.98(.90)$ & $1.60(1.03)$ & .000 \\
Link to document/source & $.85(.35)$ & $.53(.50)$ & .000 \\
Link to news site & $.63(.48)$ & $.65(.48)$ & .653 \\
Info graphics & $.28(.45)$ & $.10(.30)$ & .000 \\
Info box & $.19(.39)$ & $.24(.43)$ & .114 \\
Other sources & $.03(.17)$ & $.09(.29)$ & .000
\end{tabular}

Note. Total $\mathrm{N}=651$. Rows present results of separate $t$-Tests. Values are means with standard deviations in parentheses; Transparency Index (additive index): $0=$ minimum, $5=$ maximum; subindicators: $0=$ minimum, $1=$ maximum. 
Table 6: Regression Models for Predicting Source Transparency

\begin{tabular}{|c|c|c|c|c|c|c|c|c|c|c|c|c|}
\hline & \multicolumn{3}{|c|}{ Model 1} & \multicolumn{3}{|c|}{ Model 2} & \multicolumn{3}{|c|}{ Model 3} & \multicolumn{3}{|c|}{ Model 4} \\
\hline & $B$ & $S E(B)$ & $\beta$ & $B$ & $S E(B)$ & $\beta$ & $B$ & $S E(B)$ & $\beta$ & $B$ & $S E(B)$ & $\beta$ \\
\hline Constant & 1.72 & 0.37 & & 1.37 & 0.37 & & 1.38 & 0.42 & & 2.68 & 0.47 & \\
\hline $\begin{array}{l}\text { Journalistic } \\
\text { Professionalism }\end{array}$ & 0.64 & 0.07 & $0.37 * * *$ & 0.68 & 0.07 & $0.38 * * *$ & 0.68 & 0.07 & $0.39 * * *$ & 0.89 & 0.08 & $.51 * * *$ \\
\hline $\begin{array}{l}\text { Trust in News } \\
\text { Media }\end{array}$ & 0.23 & 0.86 & 0.01 & 0.57 & 0.84 & 0.03 & 0.62 & 0.89 & 0.03 & -2.22 & 1.01 & $-.10 *$ \\
\hline $\begin{array}{l}\text { Outlet Type } \\
\text { (NGO Model) }\end{array}$ & & & & 0.42 & 0.07 & $0.21 * * *$ & 0.42 & 0.07 & $0.21 * * *$ & 0.67 & 0.08 & $.34 * * *$ \\
\hline $\begin{array}{l}\text { Evaluation } \\
\text { (negative) }\end{array}$ & & & & & & & -0.05 & 0.07 & -0.03 & -0.04 & 0.07 & -0.02 \\
\hline $\begin{array}{l}\text { Source } \\
\text { (Politician) }\end{array}$ & & & & & & & 0 & 0.08 & 0 & -0.09 & 0.08 & -0.04 \\
\hline $\begin{array}{l}\text { NGO Model X } \\
\text { USA }\end{array}$ & & & & & & & & & & -0.84 & 0.15 & $-.31 * * *$ \\
\hline Adjusted $R^{2}$ & & & 0.13 & & & 0.17 & & & 0.17 & & & 0.21 \\
\hline$N$ & & & 651 & & & 651 & & & 651 & & & 651 \\
\hline
\end{tabular}

Note: OLS regressions. Entries are unstandardized coefficients, standard errors and betas. ${ }^{* * *} \mathrm{p}<.001, * * \mathrm{p}<.01,{ }^{*} \mathrm{p}<.0$ 
Figure 1: Means of Source Transparency per Outlet

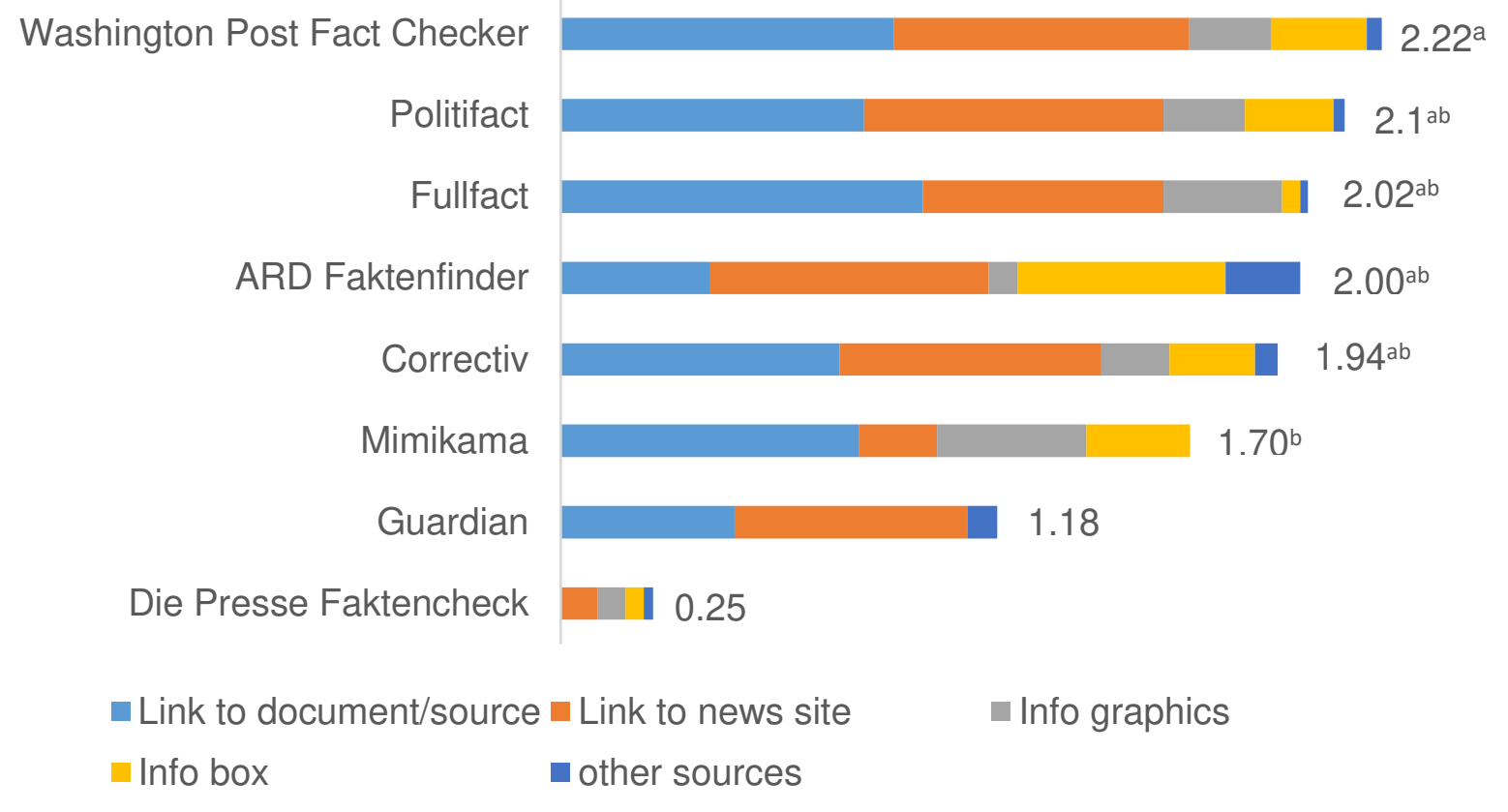

Note. Total $\mathrm{N}=651$. Bar graphs show the proportions of the individual indicators. Values at the end of the bars are mean values of the sum index (Transparency Index). Means with the same superscript are not statistically different (ANOVA, based on post hoc Gabriel's test for unequal sample sizes at $\mathrm{p}<$ .05 level). 